Arq. Bras. Med. Vet. Zootec., v.66, n.2, p.489-496, 2014

\title{
Desenvolvimento de bezerros leiteiros alimentados com silagem de leite de transição. I - Trato digestivo
}

\author{
[Development of dairy calves fed silage transition milk. I - Digestive tract] \\ R.A. Azevedo ${ }^{1}$, S.R.A. Rufino ${ }^{2}$, M.S. Cruz ${ }^{3}$, S.F. Costa ${ }^{3}$, N.J.F. Oliveira $^{2}$, S.G. Coelho ${ }^{1}$, \\ E.R. Duarte ${ }^{2}$, L.C. Geraseev ${ }^{2}$ \\ ${ }^{1}$ Escola de Medicina Veterinária - EV/UFMG - Belo Horizonte, MG \\ ${ }^{2}$ Instituto de Ciências Agrárias - ICA/UFMG - Montes Claros, MG \\ ${ }^{3}$ Universidade Federal de Lavras - UFLA - Lavras, MG
}

\begin{abstract}
RESUMO
Avaliou-se o desenvolvimento do trato digestivo de bezerros Holandeses aleitados com silagem de leite de transição. Foram utilizados 18 animais, com peso corporal inicial médio de 36,50kg $( \pm 4,03)$, alimentados individualmente em baias com concentrado, feno de Cynodon sp., água e suplemento mineral oferecidos ad libitum. $\mathrm{O}$ delineamento experimental foi inteiramente ao acaso, com três tratamentos e seis repetições. Os tratamentos consistiram em leite integral e silagem de leite de transição diluída em água ou misturada em leite, correspondendo a quatro litros diários divididos em duas refeições, durante 59 dias. Aos 60 dias, os bezerros foram abatidos e realizaram-se pesagens do trato digestivo e medidas histológicas das papilas ruminais. $\mathrm{O}$ sistema de aleitamento não interferiu nos consumos de concentrado e matéria seca total e no desenvolvimento de papilas ruminais $(\mathrm{P}>0,05)$. A silagem de leite de transição diluída em água resultou em menor peso corporal, menor peso corporal vazio e absoluto do abomaso e maior desenvolvimento intestinal. $\mathrm{O}$ aleitamento com silagem misturada em leite não comprometeu $\mathrm{o}$ desenvolvimento corporal e do trato digestivo até 60 dias de idade, representando alternativa ao aleitamento com leite.
\end{abstract}

Palavras-chave: bezerro, índice mitótico, leite, rúmen, sucedâneo

\begin{abstract}
This study aimed to evaluate the development of the digestive tract of Holstein calves which suckled milk from silage transition. We used 18 animals, with an average initial body weight of $36.50 \mathrm{~kg}( \pm 4.03)$, individually housed in pens with concentrate, hay Cynodon sp., water and mineral supplement offered ad libitum. The experimental design was completely randomized with three treatments and six replications. Treatments consisted of whole milk and silage transitional milk, diluted with water or mixed with milk, corresponding to four liters per day divided over two meals during 59 days. The food intake was monitored daily and weighed every week after the supply of liquid diet in the morning. At 60 days, the calves were slaughtered and the digestive tract was weighed and histological measures of rumen papillae were taken. The nursing system did not affect the consumption of concentrate and total dry matter and the development of rumen papillae $(P>0.05)$. The silage transition milk diluted in water resulted in lower final body weight, lower body weight and absolute emptiness abomasum and intestinal further development. Milk transition silage mixed in milk did not affect the development of the digestive tract and body until 60 days of age, representing an alternative to milk.
\end{abstract}

Keywords: calf, mitotic index, milk, milk replacer, rumen

Recebido em 22 de fevereiro de 2013

Aceito em 12 de setembro de 2013

E-mail: rafaelzooufmg@gmail.com 


\section{INTRODUÇÃO}

Ao nascerem, os bezerros apresentam características anatômicas e fisiológicas que não os caracterizam como ruminantes propriamente ditos, sendo a dieta líquida a principal fonte de nutrientes nas primeiras semanas de vida, pois o consumo de alimentos sólidos na fase inicial é insignificante (Jasper e Weary, 2002).

Durante o aleitamento ocorre o desenvolvimento funcional dos compartimentos do trato digestivo (Mancio et al., 2005) e as maiores mudanças acontecem no retículo-rúmen, o qual será colonizado por microrganismos e desenvolverá musculatura e papilas (Nussio et al., 2003). Pressões econômicas geram avanços das técnicas alimentares e de manejo na fase de cria, pois o leite utilizado pode ocasionar desvios de recursos e reduzir a lucratividade do sistema (Castro et al., 2004), devendo ser substituído por produtos de boa qualidade.

Empregar o leite de transição excedente na alimentação de bezerros pode representar alternativa racional (Arguello et al., 2003; Saalfeld et al., 2013) e viável (Ribeiro et al., 2001; Saalfeld, 2008; Azevedo et al., 2013a), porém o armazenamento desse produto não comercializável pode ser oneroso. Saalfeld (2008) propôs o acondicionamento anaeróbico em garrafas plásticas de politereftalato de etilenotipo (PET), por período mínimo de 21 dias, sendo estocado até um ano e meio em local fresco. Existem poucos trabalhos na literatura consultada a respeito da utilização da silagem de leite de transição e os seus efeitos sobre o trato digestivo durante o aleitamento de bezerros, sendo necessários estudos para aprimorar a técnica e determinar avanços do seu uso.

Objetivou-se avaliar o desenvolvimento do trato digestivo de bezerros leiteiros da raça Holandesa, aos 60 dias de idade, alimentados com silagem de leite de transição diluída em água ou misturada em leite.

\section{MATERIAL E MÉTODOS}

O experimento foi aprovado pelo Comitê de Ética em Experimentação Animal da Universidade Federal de Minas Gerais.
Após o nascimento, os bezerros permaneceram com as matrizes por $24 \mathrm{~h}$ para ingerirem colostro fornecido ad libitum. Em seguida, foram identificados e alojados no galpão experimental. No segundo dia de vida, foram alimentados com quatro litros de colostro de suas respectivas mães, às $8 \mathrm{~h}$ e às $16 \mathrm{~h}$. Foram utilizados 18 bezerros da raça Holandesa, com peso corporal inicial médio de $36,50 \pm 4,03 \mathrm{~kg}$, distribuídos em delineamento inteiramente ao acaso, com três tratamentos e seis repetições. Os animais foram mantidos em baias individuais equipadas com baldes para fornecimento de água, concentrado, feno e suplemento mineral.

As dietas foram ofertadas em volume de quatro litros, correspondentes aos tratamentos: leite, silagem de leite de transição diluída em água na proporção de 1:1 e silagem de leite de transição misturada em leite na proporção 1:1. Todos os grupos foram alimentados em duas refeições diárias de volume equivalente, às $8 \mathrm{~h}$ e às $16 \mathrm{~h}$.

Os animais dos dois grupos aleitados com silagem de leite de transição foram adaptados à dieta, acrescentando-se 12,5, 25 e $37,5 \%$ da silagem ao leite, respectivamente, no terceiro, quarto e quinto dias de idade, como indicado por Saalfeld (2008). Pela manhã foi trocada a água, e à tarde foram renovados o concentrado peletizado e o feno de tifton (Cynodon spp.), sendo ofertados ad libitum, em comedouros de plástico, ajustando-se as sobras em $200 \mathrm{~g} \mathrm{~kg}^{-1}$. Forneceu-se o suplemento mineral ad libitum. $\mathrm{O}$ leite foi obtido de vacas Holandesas de diferentes ordens e períodos de lactação. A secreção láctea de transição foi coletada conforme Saalfeld (2008), do terceiro ao sexto dia após o parto.

A composição do concentrado e do feno foram determinadas de acordo com Silva e Queiroz (2002). A composição do leite e da silagem de leite de transição foram determinadas de acordo com os métodos oficiais descritos na Instrução Normativa $\mathrm{n}^{\mathrm{o}} 68$, de 14 de abril de 2006 (Brasil, 2006) e a proteína verdadeira foi determinada subtraindo-se o valor do nitrogênio não proteico do nitrogênio total. Após esse cálculo, o resultado obtido foi multiplicado por 6,38 (Pereira et al., 2001) (Tab. 1). 
Tabela 1. Composição bromatológica do concentrado peletizado, do feno de Cynodon spp., do leite integral e da silagem de leite de transição utilizados no arraçoamento de bezerros submetidos a diferentes sistemas de aleitamento até 59 dias de idade

\begin{tabular}{lcccc}
\hline \multicolumn{1}{c}{ Constituinte } & Concentrado $^{\circledR}$ & Feno & $\begin{array}{c}\text { Leite } \\
\text { integral }\end{array}$ & $\begin{array}{c}\text { Silagem de leite de } \\
\text { transição }\end{array}$ \\
\hline Matéria Seca (\%MN) & 87,00 & 93,00 & 12,00 & 10,00 \\
Cinzas (\%MS) & 6,95 & 5,35 & - & 0,86 \\
Proteína Bruta (\%MS) & 19,00 & 12,10 & - & - \\
Proteína verdadeira (\%MS) & - & - & 3,00 & 4,19 \\
Extrato Etéreo (\%MS) & 3,00 & 1,85 & 4,70 & 3,31 \\
Cálcio (\%MS) & 0,70 & 0,41 & - & - \\
Fósforo (\%MS) & 0,51 & 0,53 & - & - \\
Fibra em detergente neutro (\%MS) & 9,2 & 60,00 & - & - \\
Fibra em detergente ácido (\%MS) & 3,5 & 23,00 & - & - \\
Lactose (\%) & - & - & 4,45 & 2,33 \\
\hline
\end{tabular}

${ }^{\circledR}$ Tecnutri Bezerro Elite, empresa Tecnutri, Montes Claros, Minas Gerais, Brasil.

Avaliaram-se o desenvolvimento corporal e o consumo de alimentos, do sexto ao $59^{\circ}$ dia de idade, totalizando 54 dias de avaliação. As sobras de concentrado e de feno foram retiradas e pesadas diariamente, para determinar o consumo diário, sendo este expresso em gramas por dia. Ao completarem 60 dias de idade, os animais foram pesados individualmente em balança previamente aferida, após jejum alimentício de $16 \mathrm{~h}$, para a obtenção do peso corporal final após o jejum (PCFJ), com livre acesso a água. Para eutanásia, administrou-se medicação pré-anestésica (cloridrato de xilazina a $2 \%$, Roumpun ${ }^{\circledR}-1,5 \mathrm{mg} / \mathrm{kg}$ de peso corporal) e anestésica geral (Pentorbabital sódico Tiopental ${ }^{\circ}, 10 \mathrm{mg} / \mathrm{kg}$ de peso corporal), seguida por sangria jugular.

Imediatamente após o abate e abertura da cavidade abdominal, procedeu-se à ligadura da porção caudal do esôfago com o cárdia, da cranial do duodeno com o esfíncter pilórico, do orifício retículo omasal assim como também do orifício omaso-abomasal. O trato gastrintestinal cheio foi removido e pesado, e posteriormente esvaziado e lavado, sendo novamente pesado, obtendo-se assim o seu peso vazio. Deduziu-se o peso do trato gastrintestinal cheio do seu peso vazio, obteve-se o peso do conteúdo do trato gastrintestinal, que, subtraído do peso corporal final após o jejum, além do conteúdo presente na vesícula biliar e na bexiga, resultou no peso corporal vazio (PCVZ) de cada animal. Os pesos do rúmen-retículo, omaso, abomaso, intestino delgado e intestino grosso foram avaliados de forma absoluta e relativa ao peso corporal final vazio (\% PCVZ).
Para a histologia, amostras de $3 \mathrm{~cm}^{2}$ da parede do recesso do rúmen foram fixadas em formalina a $10 \%$, desidratadas em séries crescentes de álcool etílico, diafanizadas em xilol, infiltradas e incluídas em parafina histológica. Os blocos de parafina foram seccionados em micrótomo manual Olympus CUT 4055, obtendo-se secções de $5 \mu \mathrm{m}$. Para análise morfométrica da altura e área das papilas ruminais e determinação do índice mitótico das células da camada basal do epitélio do rúmen, usou-se a coloração hematoxilina-eosina (HE), segundo Luna (1968). Para mensurar as áreas de epitélio total e de queratina, os cortes foram corados com Tricrômico de Masson (Luna, 1968).

Para a captura das imagens empregou-se microscópio Olympus CX31, acoplado a câmera fotográfica Olympus OSIS SC30, com o auxílio do software Cell-B (Olympus). As imagens foram analisadas e mensuradas pelo software AxioVision 4.8.2 -06/2010, da marca Carl Zeiss Images Systems®. $\mathrm{O}$ índice mitótico foi determinado pela utilização de microscópio de luz (Olympus), em aumento de 400X, sendo contadas aproximadamente 2.000 células da camada basal do epitélio, incluindo aquelas com núcleo apresentando figuras mitóticas. Calculouse o índice pelo quociente entre o número de núcleos em divisão do total contado (Costa et al., 2008; Azevedo et al., 2013b).

Procedeu-se à análise estatística em delineamento inteiramente ao acaso para as variáveis de peso corporal final e peso corporal vazio, bem como pesos dos órgãos digestivos internos, expressos de forma absoluta ou relativa, 
e as variáveis histológicas, e aplicou-se o teste de Tukey a 5\% de probabilidade (Statistical..., 2002). Os dados de consumo foram analisados em parcelas subdivididas - três sistemas nas parcelas e oito semanas nas subparcelas -, utilizando-se o teste de Tukey a 5\% de probabilidade (PROC MIXED, Statistical..., 2002). O peso corporal inicial dos bezerros foi utilizado como covariável.

\section{RESULTADOS E DISCUSSÃO}

Não houve influência $(\mathrm{P}>0,05)$ das dietas nem interação de tratamentos versus consumo de concentrado (Tab. 2). As semanas influenciaram $(\mathrm{P} \leq 0,05)$ esse parâmetro, com valores crescentes durante o período avaliado, variando entre 60,70 a 932,07g $\mathrm{dia}^{-1}$, respectivamente, para a primeira e oitava semanas de avaliação, conforme o crescimento e aumento das exigências nutricionais dos animais. Ferreira et al. (2013a) verificaram consumo de concentrado de $230 \mathrm{~g} \mathrm{dia}^{-1}$ para animais tratados com silagem de colostro diluída em água, valor inferior à média de $469,94 \mathrm{~g}$ dia $^{-1}$ verificada para os animais aleitados com silagem de leite de transição diluída em água.

Para o consumo de feno se verificou interação $(\mathrm{P} \leq 0,05)$ de dietas versus semanas de avaliação, sendo observados comportamentos de consumo diferentes dentro das semanas, entretanto, não foram verificadas diferenças entre as dietas dentro de cada semana de avaliação (Tab. 2).

Tabela 2. Médias de consumos de concentrado (CC), total de matéria seca (CTMS), final (PCF), vazio (PCVZ) e consumo de feno (CF) de bezerros Holandeses aleitados com diferentes dietas até 59 dias de idade

\begin{tabular}{|c|c|c|c|c|c|c|c|c|c|}
\hline \multicolumn{2}{|c|}{ Variáveis* } & \multicolumn{2}{|c|}{ Leite } & \multicolumn{2}{|c|}{ Silagem em água } & \multicolumn{2}{|c|}{ Silagem em leite } & \multicolumn{2}{|l|}{$\mathrm{EPM}^{1}$} \\
\hline \multicolumn{2}{|c|}{$\mathrm{CC}\left(\mathrm{g} \mathrm{MS} \mathrm{dia}^{-1}\right)$} & \multicolumn{2}{|c|}{548,62} & \multicolumn{2}{|c|}{469,94} & \multicolumn{2}{|c|}{411,50} & \multicolumn{2}{|l|}{31,45} \\
\hline \multicolumn{2}{|c|}{ CTMS (g MS dia $^{-1}$ ) } & \multicolumn{2}{|c|}{632,55} & \multicolumn{2}{|l|}{540,99} & \multicolumn{2}{|l|}{537,95} & \multicolumn{2}{|l|}{36,11} \\
\hline \multicolumn{2}{|c|}{ PCF $(\mathrm{kg})$} & \multicolumn{2}{|c|}{$78,33 \mathrm{a}$} & \multicolumn{2}{|l|}{$61,46 \mathrm{~b}$} & \multicolumn{2}{|l|}{$71,13 \mathrm{ab}$} & \multicolumn{2}{|l|}{2,77} \\
\hline \multicolumn{2}{|c|}{ PCVZ (kg) } & \multicolumn{2}{|c|}{$71,13 \mathrm{a}$} & \multicolumn{2}{|c|}{$53,39 \mathrm{~b}$} & \multicolumn{2}{|l|}{$63,60 \mathrm{ab}$} & \multicolumn{2}{|l|}{2,70} \\
\hline \multicolumn{10}{|c|}{ Interação $^{2}$} \\
\hline \multicolumn{10}{|c|}{$\mathrm{CF}\left(\mathrm{g} \mathrm{MS} \mathrm{dia}^{-1}\right)$} \\
\hline \multirow{2}{*}{ Dieta } & \multicolumn{8}{|c|}{ Semana } & \multirow{2}{*}{ EPM } \\
\hline & 1 & 2 & 3 & 4 & 5 & 6 & 7 & 8 & \\
\hline Leite & $18,27 \mathrm{Ac}$ & $44,00 \mathrm{Abc}$ & 71,54Aabc & $100,02 \mathrm{Aabc}$ & $94,63 \mathrm{Aabc}$ & $118,71 \mathrm{Aab}$ & $138,23 \mathrm{Aa}$ & $142,16 \mathrm{Aa}$ & \multirow{3}{*}{6,79} \\
\hline $\begin{array}{l}\text { Silagem } \\
\text { em água }\end{array}$ & $14,08 \mathrm{Ac}$ & $17,14 \mathrm{Ac}$ & $31,84 \mathrm{Ac}$ & $51,42 \mathrm{Abc}$ & $78,56 \mathrm{Abc}$ & $116,24 \mathrm{Aab}$ & $180,12 \mathrm{Aa}$ & $159,93 \mathrm{Aa}$ & \\
\hline $\begin{array}{l}\text { Silagem } \\
\text { em leite }\end{array}$ & $2,23 \mathrm{Ad}$ & $25,13 \mathrm{Ad}$ & 66,60Acd & $109,09 \mathrm{Abc}$ & 141,17Aabc & $162,70 \mathrm{Aab}$ & $183,89 \mathrm{Aab}$ & $190,27 \mathrm{Aa}$ & \\
\hline
\end{tabular}

${ }^{*}$ Médias seguidas de letras diferentes na linha diferem entre si; ${ }^{1} \mathrm{EPM}=$ erro padrão da média. ${ }^{2}$ Médias seguidas por letras maiúsculas diferentes na coluna ou por letras minúsculas diferentes na linha diferem entre si. As médias de CF, PCF e PCVZ foram ajustadas para a covariável peso ao nascimento $(\mathrm{P} \leq 0,05)$.

O consumo total de MS não foi influenciado $(\mathrm{P}>0,05)$ pelas dietas, sendo observado consumo médio de $570,50 \mathrm{~g} \mathrm{dia}^{-1}$. Observou-se aumento crescente $(\mathrm{P} \leq 0,05)$ no consumo total de MS com o avançar das semanas, explicado pelo crescimento dos animais e aumento de suas exigências nutricionais. Castro et al. (2004) relataram maior consumo total de MS para animais recebendo colostro fermentado, relacionando-se à deficiência energética do colostro após a fermentação, fato que não ocorreu no presente trabalho.

O peso corporal final e o peso corporal vazio diferiram $(\mathrm{P} \leq 0,05)$ entre as dietas (Tab. 2). Verificou-se que os pesos dos animais aleitados exclusivamente com leite foram mais altos que os do grupo aleitado com silagem diluída em água, e que os do grupo de silagem misturada em leite apresentaram peso similar entre ambas as dietas.

Ao diluir a silagem de leite de transição em água, na proporção de 1:1, oferta-se aos animais metade dos constituintes originais (Tab. 1), ficando a composição nutricional da dieta inferior à do leite integral. Mesmo com o menor aporte nutricional, os animais não aumentaram o consumo total de matéria seca como forma de suprir o déficit alimentar, resultando em menores pesos (Tab. 2). 
O peso absoluto do abomaso e os valores relativos do trato digestivo e dos intestinos delgado e grosso foram influenciados $(\mathrm{P} \leq 0,05)$ pelo sistema de aleitamento (Tab. 3). A diluição da silagem de leite de transição em água pode reduzir a quantidade de caseína (Ferreira et al., 2013 b), o que pode ter reduzido a coagulação do leite e provocado aumento na taxa de passagem da digesta (Lima et al., 2013), reduzindo, dessa forma, a distensão do abomaso após o aleitamento, resultando em menor desenvolvimento desse órgão (Lucci, 1989).

Segundo Ferreira et al. (2013b), a silagem de colostro apresenta alterações importantes, principalmente na composição da fração nitrogenada, que, durante o processo fermentativo, tem grande parte no nitrogênio proteico, representado principalmente pela caseína, convertido em nitrogênio não proteico.

O peso relativo do intestino delgado dos bezerros alimentados com silagem em água foi maior do que o do grupo tratado com leite. Entretanto, os tratamentos com silagem de leite de transição diluída em água ou misturada em leite apresentaram similaridade. $\mathrm{O}$ peso relativo do intestino grosso para os animais alimentados com silagem em água foi superior aos outros tratamentos (Tab. 3).

Tabela 3. Médias de peso absoluto (g) e relativos, em \% do peso corporal vazio (PCVZ), dos compartimentos do trato digestivo de bezerros Holandeses, mantidos em diferentes sistemas de aleitamento artificial, aos 60 dias de idade

\begin{tabular}{lccccc}
\multicolumn{1}{c}{ Variáveis } & Leite & Silagem em água & Silagem em leite & ${ }^{1}$ EPM & $P$ \\
\hline Trato digestivo $(\mathrm{g})$ & 4360,50 & 3881,30 & 4648,70 & 152,64 & 0,32 \\
Trato digestivo (\% PCVZ) & $6,30 \mathrm{~b}$ & $7,63 \mathrm{a}$ & $6,87 \mathrm{ab}$ & 0,19 & 0,01 \\
Rúmen-retículo (g) & 1164,20 & 1040,45 & 1072,51 & 57,94 & 0,60 \\
Rúmen-retículo (\% PCVZ) & 1,61 & 1,93 & 1,70 & 0,06 & 0,09 \\
Omaso (g) & 246,33 & 176,00 & 250,67 & 17,95 & 0,26 \\
Omaso (\% PCVZ) & 0,35 & 0,34 & 0,36 & 0,01 & 0,85 \\
Abomaso (g) & $348,50 \mathrm{a}$ & $288,66 \mathrm{~b}$ & $339,40 \mathrm{ab}$ & 10,76 & 0,03 \\
Abomaso (\% PCVZ) & 0,49 & 0,52 & 0,56 & 0,01 & 0,09 \\
Intestino Delgado (g) & 1969,70 & 1861,00 & 2192,50 & 74,19 & 0,52 \\
Intestino Delgado (\% PCVZ) & $2,85 \mathrm{~b}$ & $3,67 \mathrm{a}$ & $3,26 \mathrm{ab}$ & 0,13 & 0,04 \\
Intestino grosso (g) & 671,67 & 572,00 & 670,50 & 20,79 & 0,11 \\
Intestino grosso (\% PCVZ) & $0,98 \mathrm{~b}$ & $1,12 \mathrm{a}$ & $0,99 \mathrm{~b}$ & 0,02 & 0,01 \\
\hline
\end{tabular}

*Médias seguidas de letras diferentes na linha diferem entre si. ${ }^{1} \mathrm{EPM}=$ erro padrão da média. As médias de rúmen (g) e abomaso (\%PCVZ) foram ajustadas para a covariável peso ao nascimento $(\mathrm{P} \leq 0,05)$.

Alterações intestinais estão relacionadas às dietas fornecidas, as quais podem ter alterado a proliferação epitelial e a utilização das mesmas. A regulação do crescimento intestinal é complexa, sendo influenciada tanto por hormônios tróficos e metabólicos, além de fatores químicos e físicos da dieta (Baldwin et al., 2004).

A caseína reduzida pela conservação anaeróbica (Ferreira et al., 2013b) e coagulação insuficiente no abomaso possibilita maior passagem dessa proteína íntegra para o sítio digestivo, podendo sobrecarregá-lo, ocasionando menor aproveitamento da dieta líquida (Lima, 2008). O aumento na velocidade de passagem da digesta para o intestino delgado pode modificar a secreção de hormônios metabólicos e gastrintestinais, alterando o desenvolvimento funcional e os processos digestivos e absortivos (Le Drean et al., 1998), justificando as diferenças de peso relativo dos intestinos (Tab. 3 ).

A similaridade $(\mathrm{P}>0,05)$ para a maioria dos pesos percentuais das porções digestivas entre os tratamentos com leite e silagem de leite de transição diluída em água ou misturada em leite relacionam-se aos resultados semelhantes dos consumos de concentrado e total de matéria seca (Tab. 2). Diferenças entre os pesos dos compartimentos dos pré-estômagos dos ruminantes geralmente refletem as variações no consumo alimentar e no padrão fermentativo ruminal (Bittar et al., 2009). Segundo Baldwin et al. (2004), o desenvolvimento do rúmen associase à ingestão de dieta sólida e à produção de ácidos graxos voláteis de cadeia curta. 
O tamanho e a área das papilas ruminais foram similares $(\mathrm{P}>0,05)$ entre as dietas avaliadas (Tab. 4), associando-se aos consumos de concentrado e total de matéria seca semelhantes entre os grupos (Tab. 2). Segundo Quigley (1997) e Bittar et al.
(2009), o desenvolvimento adequado das papilas resulta da ação de produtos de fermentação ruminal e estímulo físico a partir do alimento consumido.

Tabela 4. Médias de altura das papilas ruminais em micrômetros $(\mu \mathrm{m})$, áreas em micrômetros quadrados $\left(\mu \mathrm{m}^{2}\right)$ de papilas, epitelial, queratinização e índice mitótico da camada basal do epitélio ruminal de bezerros Holandeses, criados em diferentes sistemas de aleitamento artificial, aos 60 dias de idade

\begin{tabular}{lccccc}
\multicolumn{1}{c}{ Variáveis } & Leite & $\begin{array}{c}\text { Silagem em } \\
\text { água }\end{array}$ & $\begin{array}{c}\text { Silagem em } \\
\text { leite }\end{array}$ & ${ }^{1}$ EPM & $P$ \\
\hline Altura das papilas ruminais $(\mu \mathrm{m})$ & 23,83 & 34,14 & 27,47 & 2,89 & 0,35 \\
Área das papilas ruminais $\left(\mu \mathrm{m}^{2}\right)$ & 171,98 & 240,59 & 187,59 & 19,25 & 0,33 \\
Área de epitélio ruminal $\left(\mu \mathrm{m}^{2}\right)$ & $173,46 \mathrm{a}$ & $116,18 \mathrm{ab}$ & $98,17 \mathrm{~b}$ & 13,20 & 0,04 \\
Área de queratina papilar ruminal $\left(\mu \mathrm{m}^{2}\right)$ & $43,13 \mathrm{a}$ & $26,64 \mathrm{~b}$ & $17,11 \mathrm{~b}$ & 3,04 & 0,01 \\
Índice mitótico da camada basal $(\%)$ & $0,54 \mathrm{~b}$ & $1,04 \mathrm{a}$ & $0,70 \mathrm{ab}$ & 0,07 & 0,01 \\
\hline
\end{tabular}

"Médias seguidas de letras diferentes na linha diferem entre si; ${ }^{1} \mathrm{EPM}=$ erro padrão da média.

As áreas de epitélio ruminal total, de queratina do epitélio das papilas e o índice mitótico das células basais do epitélio ruminal foram influenciados $(\mathrm{P} \leq 0,05)$ pelos aleitamentos, sendo que os animais aleitados com leite apresentaram área de epitélio e de queratina superior e menores índices mitóticos (Tab. 4). Os animais alimentados com silagem de leite de transição diluída em água apresentaram maiores índices se comparados aos aleitados com leite, indicando maior atividade proliferativa do epitélio ruminal. Esse aumento não era esperado, uma vez que os animais apresentaram consumo total de matéria seca semelhante aos outros grupos (Tab. 2).

Substâncias intrínsecas e extrínsecas podem ter influenciado a proliferação e a diferenciação epitelial. Alguns autores relatam que os hormônios da tireoide, hidrocortisona, insulina e prolactina, os fatores de crescimento epidérmico e de transformação do crescimento, micronutrientes, vitamina $\mathrm{D}_{3}$ e ácido retinóico (Staiano-Coico et al., 1990; Pollitt, 1996; Suter et al., 1997; Silper, 2012) podem alterar a proliferação e a constituição epitelial ruminal. Entretanto, esses parâmetros não fizeram parte do objetivo deste estudo.

\section{CONCLUSÕES}

O fornecimento de silagem de leite de transição diluída em água ou misturada em leite não influenciou o consumo total de matéria seca pelos animais, o que não resultou em alterações no peso dos pré-estômagos. Entretanto, a diluição em água proporcionou menores pesos corporais final e vazio, menor peso do abomaso, maior desenvolvimento intestinal e maior índice mitótico das células basais do epitélio ruminal.

\section{AGRADECIMENTOS}

À Fazenda Experimental Professor Hamilton de Abreu Navarro (FEHAM) do ICA/UFMG. Ao suporte financeiro do Conselho Nacional de Desenvolvimento Científico e Tecnológico (CNPq), da Fundação de Amparo à Pesquisa do Estado de Minas Gerais (FAPEMIG) e da empresa Tecnutri Tecnologia em Nutrição Animal.

\section{REFERÊNCIAS}

ARGUEllo, A.; CASTROA, N.; CAPOTEB, J. et al. Effects of refrigeration, freezing-thawing and pasteurization on IgG goat colostrums preservation. Small Rumin. Res, v.48, p.135-139, 2003.

AZEVEDO, R.A.; ARAÚJO, L.; COELHO, S.G.; et al. Desempenho de bezerros alimentados com silagem de leite de transição. Pesqui. Agropec. Bras., v.48, p.545-552, 2013 a.

AZEVEDO, R.A.; ARAÚJO, L.; DUARTE, D.V. et al. Desenvolvimento do trato digestivo de bezerros leiteiros criados em sistema de aleitamento fracionado. Pesqui. Vet. Bras., v.33, p.931-936, 2013b. 
BALDWIN, R.L.; McLEOD, K.R.; KLOTZ, J.L. et al. Rumen development, intestinal growth and hepatic metabolism in the pre- and postweaning ruminant. J. Dairy Sci., v.87, p.55-65, 2004.

BITTAR, C.M.M.; FERREIRA, L.S.; SANTOS, F.A.P. et al. Desempenho e desenvolvimento do trato digestório superior de bezerros leiteiros alimentados com concentrado de diferentes formas físicas. Rev. Bras. Zootec., v.38, p.15611567, 2009.

BRASIL. Ministério da Agricultura, Pecuária e Abastecimento. Instrução Normativa $\mathrm{n}^{\circ}$ 68, de 12 de dezembro de 2006. Oficializa os Métodos Analíticos Oficiais Físico-Químicos, para Controle de Leite e Produtos Lácteos, em conformidade com o anexo desta Instrução Normativa, determinando que sejam utilizados nos Laboratórios Nacionais Agropecuários. Diário Oficial da União, Brasília, 14 de dezembro de 2006, Seção I, p.8.

CASTRO, A.L.M.; CAMPOS, W.E.; MANCIO, A.B. et al. Desempenho e rendimento de carcaça de bezerros alimentados com colostro fermentado, associado ao óleo de soja e zeranol. Arq. Bras. Med. Vet. Zootec., v.56, p.193-201, 2004.

COSTA, S.F.; PEREIRA, M.N.; MELO, L.Q. et al. Alterações morfológicas induzidas por butirato, propionato e lactato sobre a mucosa ruminal e a epiderme de bezerros. I. Aspectos histológicos. Arq. Bras. Med. Vet. Zootec., v.60, p.1-9, 2008.

FERREIRA, L.S.; BITTAR, C.M.M.; SILVA, J.T.; et al. Desempenho e parâmetros sanguíneos de bezerros leiteiros que receberam sucedâneo lácteo ou silagem de colostro. Arq. Bras. Med. Vet. Zootec., v.65, p.1357-1366, 2013 a.

FERREIRA, L.S.; SILVA, J.T.; PAULA, M.R.D.; et al. Colostrum silage: fermentative, microbiological and nutritional dynamics of colostrum fermented under anaerobic conditions at different temperatures. Acta. Sci. Anim. Sci., v.35, p.395-401, 2013 b.

JASPER, J.; WEARY, D.M. Effects of ad libitum milk intake on dairy calves. J. Dairy Sci., v.85, p.3054-3058, 2002.
LE DREAN, G.; LE HUEROU-LURON, I.; GESTIN, M. et al. Comparison of the kinetics of pancreatic secretion and gut regulatory peptides in the plasma of preruminant calves fed milk or soybean protein. J. Dairy Sci., v.81, p.13131321, 1998.

LIMA, P.O. Substituição parcial do leite por soro de queijo e ovo na dieta líquida de bezerros leiteiros. 2008. 123f. Tese (Doutorado em Zootecnia) - Universidade Federal do Ceará, CE.

LIMA, P.D.O.; LIMA, R.N.D.; MIRANDA, M.V.F.G.D. et al. Development of the stomachs of calves receiving different liquid diets. Cienc. Rural, v.43, p.716-721, 2013.

LUCCI, C. Bovinos leiteiros jovens: nutrição, manejo, doenças. São Paulo: Nobel, 1989. 371p.

LUNA, L.G. Manual of histologic staining methods of the Armed Forces Institute of Pathology. 3.ed. New York: Mc Graw, 1968. 258p.

MANCIO, A.B.; GOES, R.H.T.B.; CASTRO, A.L.M. et al. Colostro fermentado, associado ao óleo de soja e promotor de crescimento, em substituição ao leite, na alimentação de bezerros mestiços leiteiros. Rev. Bras. Zootec., v.34, p.1314-1319, 2005.

NUSSIO, C.M.B.; SANTOS, F.A.P.; ZOPOLLATTO, M. et al. Parâmetros de fermentação e medidas morfométricas dos compartimentos ruminais de bezerros leiteiros suplementados com milho processado (Floculado vs. Laminado a vapor) e monensina. Rev. Bras. Zootec., v.32, p.1021-1031, 2003.

PEREIRA, D.B.C.; SILVA, P.H.F.; COSTA Jr., L.C.G. et al. Físico-química do leite e derivados: métodos analíticos. Juiz de Fora: Epamig, 2001. 234p.

POLLITT, C.C. Basement membrane pathology: a feature of acute equine laminitis. Equine Vet. J., v.28, p.38-46, 1996.

RIBEIRO, T.R.; PEREIRA, J.C.; LEÃO, M.I. et al. Tamanho de órgãos e vísceras de bezerros holandeses, para produção de vitelos recebendo dietas com diferentes níveis de concentrado. Rev. Bras. Zootec., v.30, p.2163-2168, 2001. 
QUIGLEY, J.D. Does hay develop the rumen? APC calf notes. 1997. Disponível em: <http://www.calfnotes.com/pdffiles/CN019.pdf >. Acessado em: 15 jan. 2013.

SAALFELD, M.H. Uso da Silagem de colostro como substituto do leite na alimentação de terneiras leiteiras. Hora Vet., v.162, p.59-62, 2008.

SAALFELD, M.H.; PEREIRA, D.I.B.; SILVEIRA, K.R.K. et al. Anaerobically fermented colostrum: an alternative for feeding calves. Cienc. Rural, v.43, p.1636-1641, 2013.

SILPER, B.F. Efeitos de três estratégias de aleitamento sobre ganho de peso, desenvolvimento ruminal e perfil metabólico e hormonal de bezerros Holandeses. 2012. $96 \mathrm{f}$. Dissertação (Mestrado em Zootecnia) - Escola de Veterinária, Universidade Federal de Minas Gerais, Belo Horizonte, MG.
SILVA, D.J.; QUEIROZ, A.C. Análise de alimentos: métodos químicos e biológicos. 3.ed. Viçosa: UFV, 2002. 235p.

STAIANO-COICO, L.; KHANDKE, K.; KRANE, J.F. et al. TGF-alpha and TGF-beta expression during sodium-N-butyrate-induced differentiation of human keratinocytes: evidence for subpopulations-specific up-regulation of TGF-beta mRNA in suprabasal cells. Expl. Cell Res., v.191, p.286-291, 1990.

STATISTICAL Analisys Sistem - SAS Institute Inc. SAS ${ }^{\circledR}$ User's Guide: Statistics, Version 9 Edition. Cary, NC: SAS Institute Inc., 2002.

SUTER, M.M.; CRAMERI, F.M.; OLIVRY, T. et al. Review article: Keratinocyte biology and pathology. Vet. Dermatol., v.8, p.67-100, 1997. 